\title{
A compact dual band PIFA antenna for GPS and ISM BAND applications
}

\author{
Samir El Kilani ${ }^{1}$, Larbi El Abdellaoui ${ }^{2}$, Jamal Zbitou ${ }^{3}$, A.Errkik ${ }^{4}$, Mohamed Latrach ${ }^{5}$ \\ ${ }^{1,2,3,4}$ LMEET FST of Settat, University of Hassan 1st, Morocco \\ ${ }^{5}$ Microwave group, ESEO ANGERS, France
}

\begin{tabular}{l} 
Article Info \\
\hline Article history: \\
Received Sep 16, 2018 \\
Revised Nov 17, 2018 \\
Accepted Dec 16, 2018 \\
\hline
\end{tabular}

Keywords:

Blutooth/wifi

GPS

Microstrip patch antenna

Multiband antennas

PIFA

\section{Corresponding Author:}

Samir El Kilani,

LMEET FST of Settat,

University of Hassan 1st, Morocco.

Email: dr.samir.2014@gmail.com

\begin{abstract}
This work deals with desgin of a novel compact Dual band PIFA Antenna structure. The proposed antenna is validated for GPS and WIFI applications. The antenna is achieved on a lossy FR4 substrate. The final size of the antenna is $100 \times 55 \times 13.235 \mathrm{~mm} 3$. The final antenna structure was optimized and validated into simulation, fabrication and test. The proposed multiband PIFA is optimized by using solts technique. The fabricated antenna is validated to cover the operating frequencies of GPS $(1.535-1.7 \mathrm{GHz})$ and BLUTOOTH/WIFI (2.54-2.47GHz) bands
\end{abstract}

Copyright $@ 2019$ Institute of Advanced Engineering and Science. All rights reserved.

\section{INTRODUCTION}

Actually, the developpement of mobile stations and equipment for wirless communications have known many update working in many frequency bands. Thedeamand then for multiband componentsis increasing which will permit to miniature the final wireless device. Among the critical circuits for wireless communications we find the antenna, thererfore to communicate in serveral frequency bands we need to have a multiband antenna which reduce significantly the seize of a mobile wireless device. To achieve such circuit, we can find different methods and techniques which can be used like the use of slot techniques [1]-[3] and fractal technique [4]. Among the common multiband antennas we find the IFA [5]-[9]. In this paper we have conducted a study on the design of a new antenna structure which can operate in the GPS and ISM "Industrial and Medical Bands". The following sections will describe how to design such circuit.

\section{PLANAR INVERTED F ANTENNAS}

The Inverted F Antenna (IFA) as shown in Figure 1, typically consists of a rectangular planar element located above a ground plane, a short circuiting plate or pin, and a feeding mechanism for the planar element. 


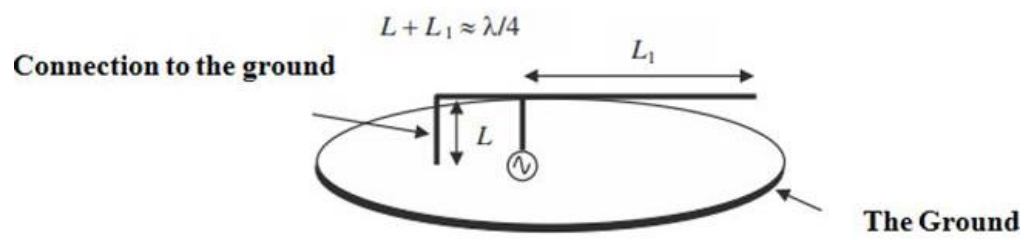

Figure 1. Structure of the IFA

The substrate used is usualy the air in order to improve the performances of the antenna. This is in fact placed at a point where the electric field of the fundamental mode is zero. Now for the PIFA as depicted in Figure 2, the principle of these antenna has been widely exploited in the literature. This kind of Antennas is Multi-band and have been developed for mobile phone applications. As mentioned in Figure 2, the PIFA Antennas are then associated with slots, capacitive loads and parasitic patches Short-circuited to achieve a multiband behavior.

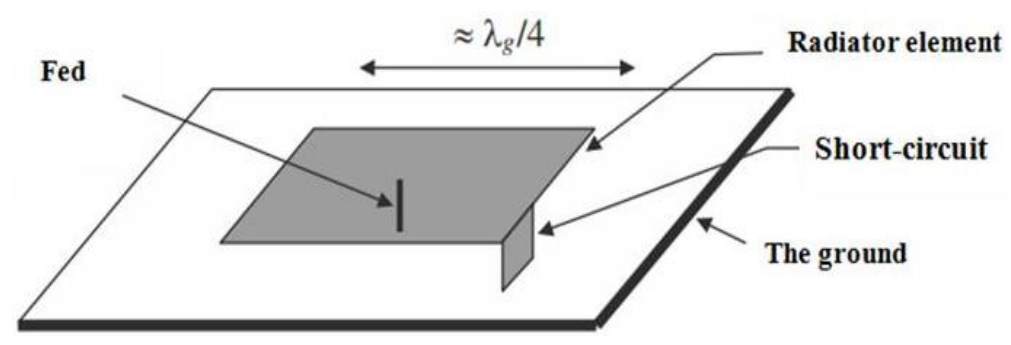

Figure 2. Structure of the PIFA [1]

The input impedance matching is adjusted by positioning the feed point and the shorting pin

\section{DESIGN PROCEDURES}

In order to design the PIFA proposed antenna, we have strated this study by using the optimization methods integrated in the electromagnetic solver. The antenna is designed and mounted on a lossyFR4 substratewith a thickness of $1.6 \mathrm{~mm}$, a dielectric relative permittivity $\varepsilon_{\mathrm{r}}=4.4$, and loss tangent of 0.025 . After many series of optimization we have developed and validated the antenna presented in Figure 3. This figure illustrates the different views.

$\mathbf{L}$

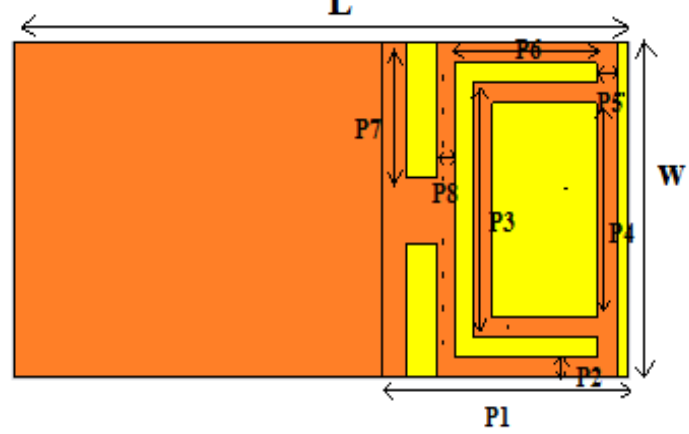

(a) Top view

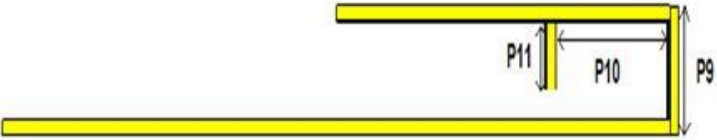

(b) Side view

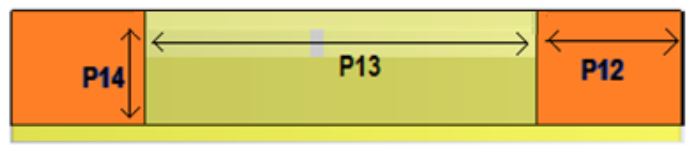

(c) Left view

Figure 3. Geometry of the proposed multiband PIFA antenna 
The radiator the position the feed probe was optimized following a parametric study on the position of the probe and the hight of P11 face. The input impedance is matched for $50 \mathrm{Ohm}$. The radiating element and the short-circuit plate are all having $0.035 \mathrm{~mm}$ as a metal thickness the different optimized parameters are listed in Table1.

Table 1. Parameters of the Proposed Antenna (unit in $\mathrm{mm}$ )

\begin{tabular}{cccc}
\hline Parameter & Value & Parameter & Value \\
\hline L & 100 & P7 & 20 \\
W & 55 & P8 & 3 \\
P1 & 38.4 & P9 & 13.235 \\
P2 & 3 & P10 & 26.765 \\
P3 & 38 & P11 & 4 \\
P4 & 32 & P12 & 13.5 \\
P5 & 3 & P13 & 23 \\
P6 & 23 & P14 & 13.235 \\
\hline
\end{tabular}

As presented in Figure 4, the optimized proposed antenna presents a good matching input impedance for three bands GPS at $1.57 \mathrm{GHz}$, ISM at $2.45 \mathrm{Ghz}$ and Wlan at $3.8 \mathrm{GHz}$ with level of the reflection coefficient which is below $-10 \mathrm{~dB}$.

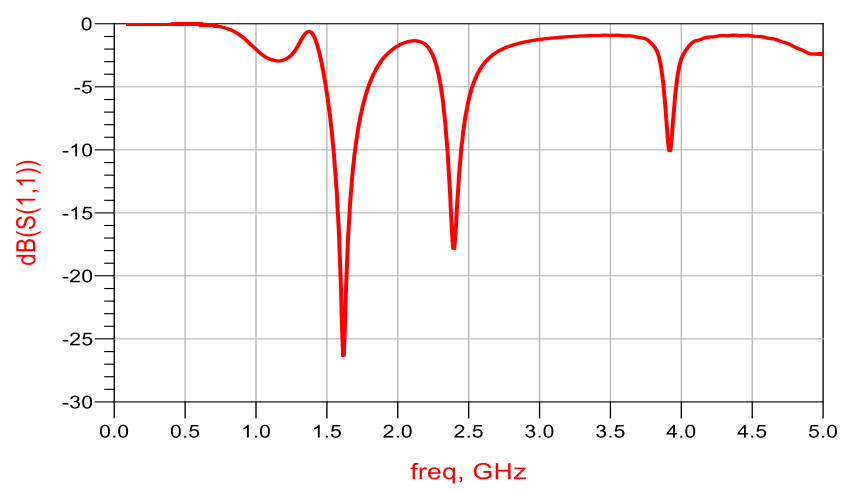

Figure 4. Reflection coefficient of the proposed multiband PIFA Antenna versus frequency

Figure 5 shows the simulated three-dimensional 3D radiation patterns of the proposed antenna at three resonant frequencies $1.65 \mathrm{GHz}$ and $2.458 \mathrm{GHz}$. We can conclude that the proposed antenna can radiate Bidirectional pattern at all the operating frequency bands.

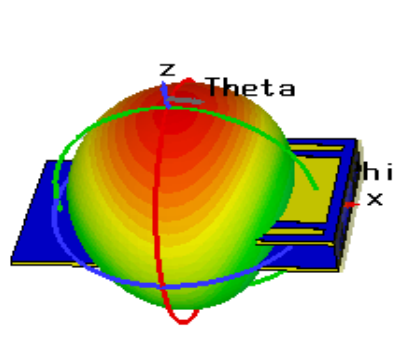

1.65 GHz

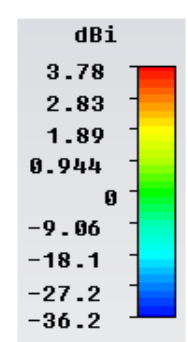

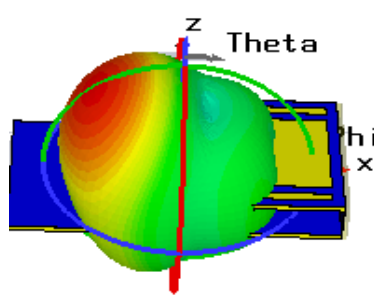

$2.458 \mathrm{GHz}$

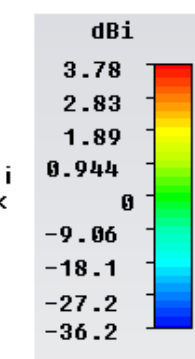

Figure 5. The simulated radiation patterns of the proposed multiband PIFA antenna at different resonant frequencies 
And for the surface current density, Figure 6 shows the simulated surface current distributions of the multiband planar antenna at three resonant frequencies $1.65 \mathrm{and} \mathrm{GHz}, 2.458 \mathrm{GHz}$. As we can see the surface current are concentrated around the radiating element.

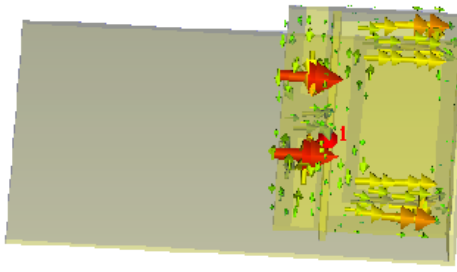

$1.65 \mathrm{GHZ}$

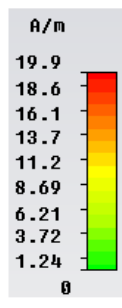

(

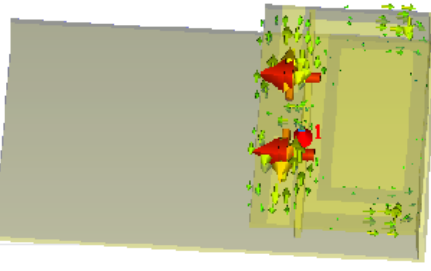

$2.458 \mathrm{GHz}$

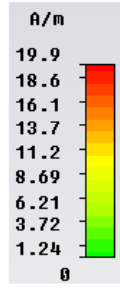

Figure 6. Simulated surface current of the proposed multiband PIFA antenna at different resonant frequencies

\section{FABRICATION AND TEST}

After the validation of the PIFA antenna into simulation, we have conducted the achievement and fabrication of the final circuit as depicted in Figure 7. The fabrication of such volume isn't easy because we have fabricated each face separately and after that we have associated them.

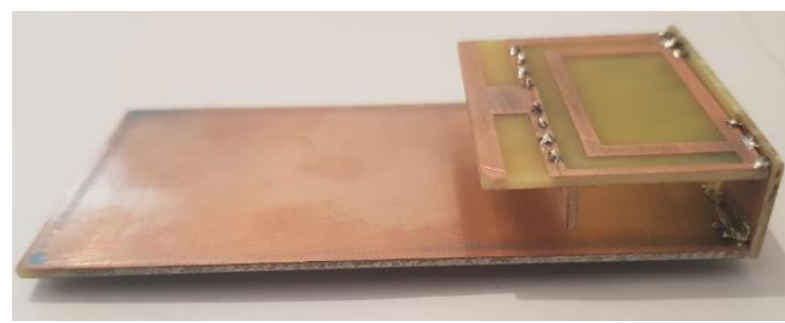

Figure 7. Photograph of the fabricated PIFA antenna

The problem of such realization is that we have a 3D structure which can influence the precision After the assoiciation of each face we have tested this antenna by using a Vector Network Analyser from Agilent with $3.5 \mathrm{~mm}$ calibration Kit. As shown in Figure 8, the antenna operates in three bands, the first one is $[1.535-1.7 \mathrm{GHz}]$ the second one is $[2.54-2.47 \mathrm{GHz}]$, and the third one is reserved for the Wlan around 3.8 $\mathrm{GHz}$. As illustrated in the comparaison between simulation and measurement results we can conclude that we have a good agreement which valid the multiband behavior of the proposed PIFA antenna.

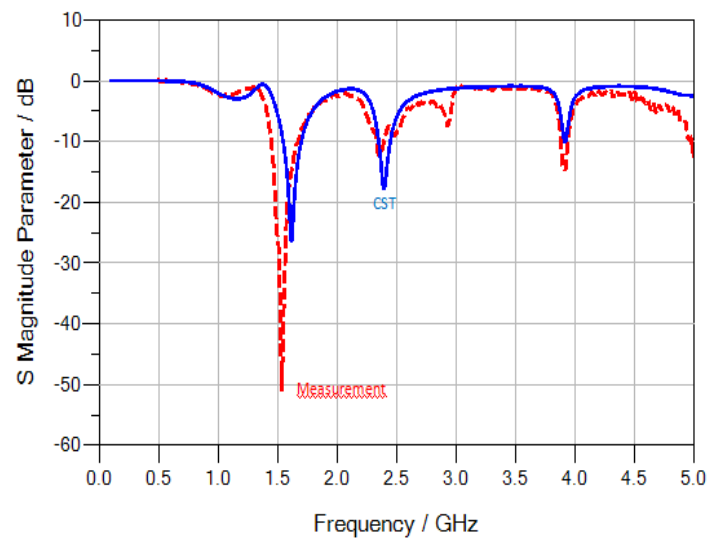

Figure 8. Comparaison between simulation and measurement of the reflection coefficient 
The radiating patern of the manufactured antenn has been measured inside the anechoic chamber fort the frequencies: $1.45,1.535,1.657,2.363,2.485 \mathrm{GHz}$ in E_plane and H_plane. In the H_plane the antenna presents a bidirectional pattern, in all frequencies existing in the operating spectrum, due to ground chosen in the bottom of the substrate. Also the radiation is bidirectional in E_plane in the frequencies 1.45 , 1.535, 1.657 GHz. Radiating patern as shown in Figure 9 and 10.
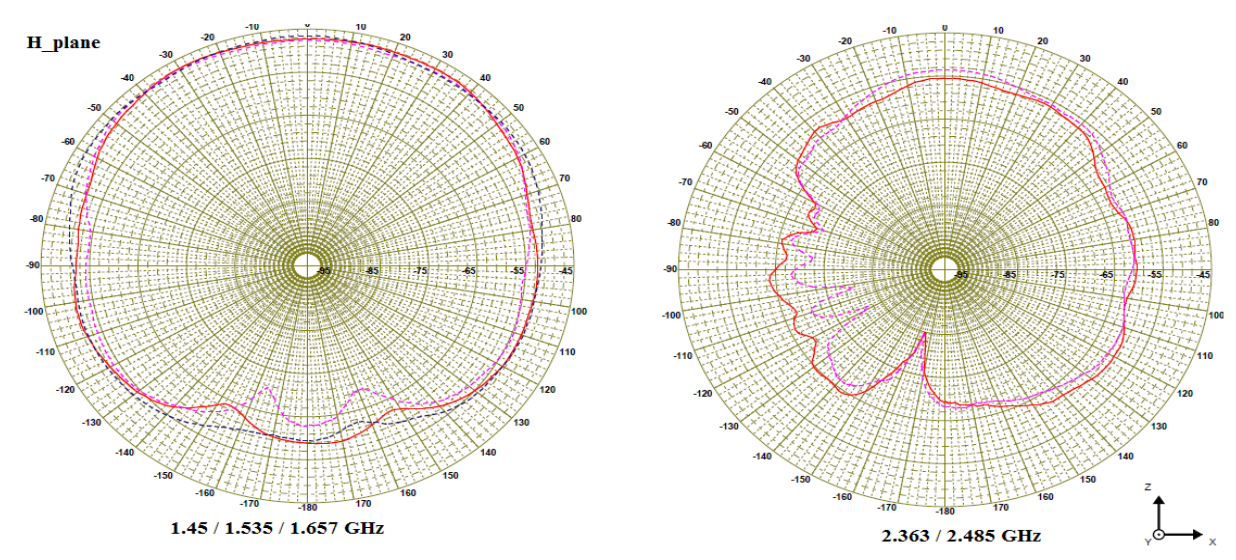

Figure 9. Radiating patern of $1.45,1.535,1.657,2.363,2.485 \mathrm{GHz}$ in H_plane
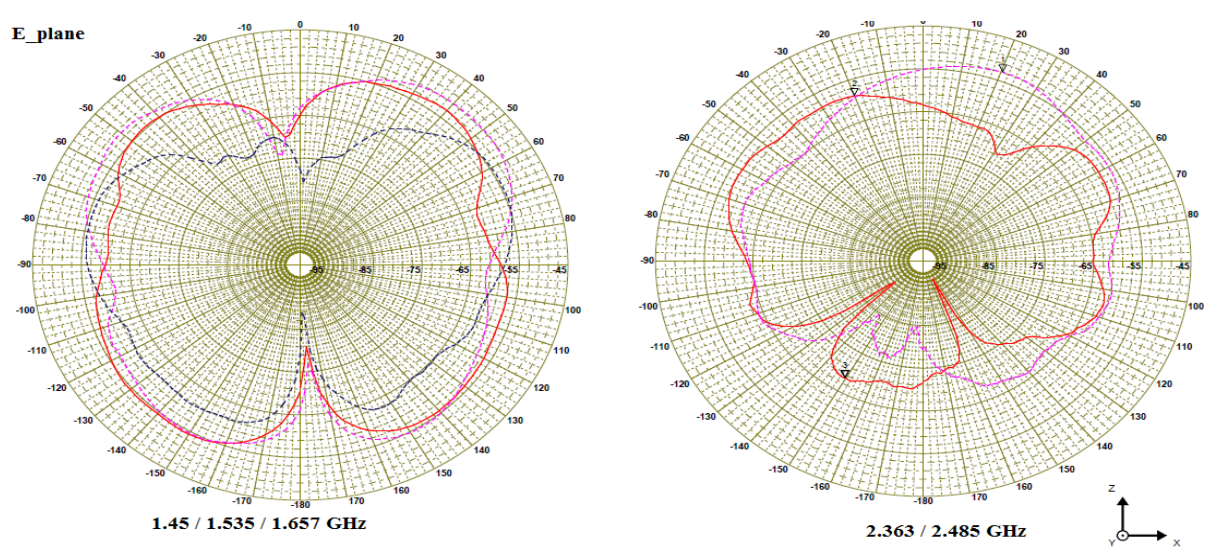

Figure 10. Radiating patern of 1.45, 1.535, 1.657, 2.363, 2.485 GHz in E_plane

\section{CONCLUSION}

This work has presented a new stduy on a new configuration of PIFA, the proposed antenna was validated in simulation, by fabrication and test. The final circuit operates in three frequency bands (1.535-1.7GHz), (2.54-2.47GHz) bands which covers GPS /BLUTOOTH/WIFI for mobile communications. and for Wlan. The fabricated antenna is tested in Anechoic chamber which validate the radiation pattern of the antenna which is bidirectionalfor the different frequency band. This antenna can be designed following the same steps for other frequency bands.

\section{REFERENCES}

[1] K. Rama Krishna, G Sambasiva Rao, P.R.Ratna Raju, " Design and Simulation of Dual Band Planar Inverted F Antenna (PIFA) For Mobile Handset Applications" International Journal of Antennas (JANT) Vol.1, No.1, October 2015.

[2] I. Zahraoui, A. Errkik, M. C. Abounaima, A. Tajmouati, L. E. Abdellaoui, M. Latrach” A New Planar Multiband Antenna for GPS, ISM and WiMAX Applications"' International Journal of Electrical and Computer Engineering (IJECE), Vol. 7, No. 4, August 2017, pp. 2018-2026.

[3] S. Yang, C. Zhang, H. Pan, A. Fathy and V. Nair, "Frequency-reconfigurable antennas for multiradio wireless platforms," IEEE Microwave Magazine, vol. 10, pp. 66-83, 2009. 
[4] Yi Huang, Kevin Boyle "Antennas From Theory To Practice " first published 2008, a John Wiley and Sons, Ltd, Publication.

[5] S. S. lodhi, P.K. Singhal, V.V. Thakare, "Design and Analysis of Tripple Band Koch Fractal Yagi UdaAntenna,"International Journal of Electrical and Computer Engineering (IJECE), Vol. 3, No. 4, August 2013, pp. 456-460.

[6] Z. Li and Y. Rahmat-Samii, "Whip-PIFA combination in wireless handset application: A hybrid circuit model and full wave analysis," in IEEE AP-S Int. Symp. Dig., vol. 3, 2004, pp. 2747-2750.

[7] T. Taga, "Performance analysis of a build-in planar inverted F antenna for $800 \mathrm{MHz}$ band portable radio units," IEEE J. Select. Areas Commun.,vol. SAC-5, pp. 921-929, Jun. 1987.

[8] Iulian Rosu, YO3DAC / VA3IUL "PIFA - Planar Inverted F Antenna" http://www.qsl.net/va3iul

[9] P.J. Soh, G.A.E. Vandenbosch, S.L. Ooi, and M.R.N., Husna, "Wearable dual-band Sierpinski fractal PIFA using conductive fabric," Elect. Lett., vol. 47, no. 6, pp. 365-367, May 2011.

[10] P. J. Soh, G. A. E. Vandenbosch, S. L. Ooi, and M. R. N. Husna, "Design of a broadband all-textile slotted PIFA," IEEE Trans. Antennas Propag., vol. 60, no. 1, pp. 379-384, Jan. 2012.

\section{BIOGRAPHIES OF AUTHORS}

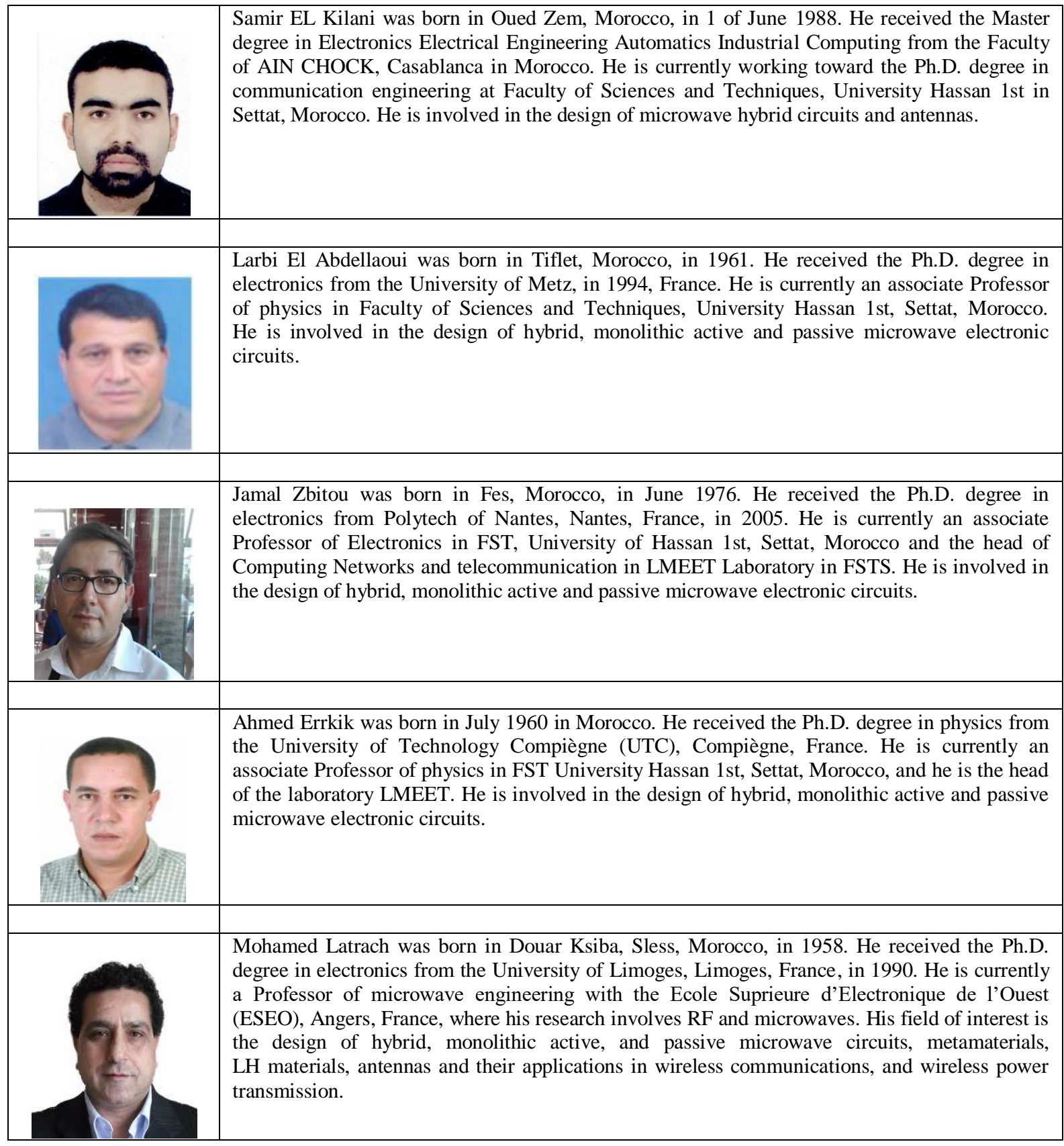

